\title{
A AUTORIA DO CLG: UMA ANÁLISE À LUZ DO CONCEITO FOUCAULTIANO DE FUNÇÃO AUTOR
}

\section{THE AUTORSHIP OF THE CLG: AN ANALYSIS IN THE LIGHT OF THE FOUCAULDIAN CONCEPT OF AUTHOR FUNCTION}

\author{
Micaela Pafume Coelho \\ Universidade Federal de Uberlândia (UFU) \\ Instituto Federal de Mato Grosso (IFMT)
}

\section{RESUMO}

Neste trabalho, partimos da discussão sobre o conceito de função autor, estabelecida por Foucault (1969), para mostrar que é possível sustentar, com efeito, a atribuição da autoria do Curso de Linguística Geral a Ferdinand de Saussure, dado que um autor não deve ser entendido como o indivíduo que pronuncia ou escreve um texto, mas como aquilo que dá unidade a um discurso específico.

PALAVRAS-CHAVE: Saussure; Foucault; Curso de Linguística Geral; autor.

\begin{abstract}
The starting point of this work is the concept of author function stablished by Foucault (1969). Based on this concept, we aim to demonstrate that is effectively possible to support the authorship of the Course in General Linguistics attributed to Ferdinand de Saussure. This is because, according to Foucault, an author must not be understood as a person that pronounces or writes a text; actually, it must be comprehended as a series of elements that give unity to a specific discourse.
\end{abstract}

KEYWORDS: Saussure; Foucault; Course in General Linguistics; author.

\section{INTRODUÇÃO}

A discussão sobre o conceito de função autor perpassa alguns dos trabalhos de Foucault, apresentando um tratamento de cunho mais vertical em seu trabalho intitulado "O que é um autor", de 1969. Analisar a relação entre obra e autoria se mostra relevante para os estudos discursivos, pois leva à reflexão acerca da distinção entre os discursos cotidianos e os discursos que, por razões históricas, conjunturais, técnicas e institucionais recebem um nome de autor, ou seja, dispõe da função enunciativa chamada de "função autor".

No início do século XX, foi publicado o "Curso de Linguística Geral” (CLG) - livro cujo processo de elaboração se deu de forma peculiar, uma vez que não foi efetivamente escrito pelo autor que lhe é atribuído: Ferdinand de Saussure. Tal livro apresenta em seu conteúdo um discurso que, com efeito, não se confunde com os discursos cotidianos. Entretanto, as peculiaridades de sua edição levaram os estudiosos das reflexões saussurianas a tomarem posicionamentos distintos quanto à autoria do livro: muitos concordam que Saussure seja, de

\footnotetext{
${ }_{1}^{1}$ Doutoranda em Estudos Linguísticos pelo Programa de Pós-graduação em Estudos Linguísticos da Universidade Federal de Uberlândia (PPGEL-UFU). Professora do Instituto Federal de Mato Grosso (IFMT). O presente trabalho foi realizado com apoio da Coordenação de Aperfeiçoamento de Pessoal de Nível Superior - Brasil (CAPES) Código de Financiamento 88881.190156/2018-01.
} 
fato, seu autor, porém, alguns têm se posicionado de maneira contrária, contestando essa atribuição.

Desse modo, neste trabalho, procuraremos analisar a questão da autoria do CLG considerando os posicionamentos antagônicos que surgiram a esse respeito. A partir disso, buscaremos, nos trabalhos de Foucault que tratam da função autor, refletir sobre a possibilidade - ou impossibilidade - de considerar Saussure, de fato, como autor do livro em questão. Para tanto, primeiramente exporemos alguns elementos relevantes para a compreensão do contexto de elaboração do CLG, bem como as razões que motivaram seus editores a conceder inteiramente a autoria do livro a Saussure. Em seguida, abordaremos os posicionamentos de Bouquet (1997; 2002) e Normand (2009), a respeito da legitimidade do CLG e da fidelidade dos editores às reflexões saussurianas. Após isso, faremos um breve levantamento do conceito de função autor em Foucault (1969; 1970), a fim de embasar nossa análise das questões que envolvem Saussure, considerado como autor do CLG.

\section{A edição do Curso de Linguística Geral}

O CLG consiste no livro responsável por levar a público a teorização de Ferdinand de Saussure, a qual permitiu a fundação da Linguística Moderna, no início do século XX. Embora tenha sua autoria concedida ao linguista, o livro não foi de fato escrito por ele; trata-se de uma edição póstuma, feita por dois colegas de Saussure - C. Bally e A. Sechehaye - a partir de poucas notas autógrafas do linguista, e, principalmente, das anotações de alguns participantes dos cursos ministrados por ele na Universidade de Genebra, entre 1907 e 1911.

Assim, essas anotações, feitas pelos participantes dos cursos de Saussure, consistiram nas principais fontes de elaboração do CLG, fato que concedeu à edição uma peculiaridade que não muito comumente caracteriza os livros fundadores das áreas do conhecimento. Segundo os editores, a necessidade de tomar como principal base da edição essas anotações, e não aquelas do próprio Saussure, se deu pelo seguinte motivo:

Após a morte do mestre, esperávamos encontrar-lhe nos manuscritos, cortesmente postos à nossa disposição por Mme de Saussure, a imagem fiel ou pelo menos suficientemente fiel de suas geniais lições; entrevíamos a possibilidade de uma publicação fundada num simples arranjo de anotações pessoais de Ferdinand de Saussure, combinadas com as notas dos estudantes. Grande foi nossa decepção; não encontramos nada ou quase nada que correspondesse aos cadernos de seus discípulos; (BALLY, SECHEHAYE, 1916 [2006], p. 1, grifo nosso)

O conteúdo dos manuscritos de Saussure cedidos aos editores por sua esposa quase não apresentava correspondência com o conteúdo apresentado nos cadernos daqueles que estiveram nos cursos. Desse modo, Bally e Sechehaye decidiram organizar uma edição pautada principalmente nas anotações feitas por aqueles que presenciaram os cursos, uma vez que a contribuição original de Saussure para a Linguística era mostrada mais em suas aulas do que nos manuscritos que estavam em posse dos editores. Eles, então, optaram por elaborar uma

[...] recriação, tanto mais árdua quanto deveria ser inteiramente objetiva; em cada ponto, penetrando até o fundo de cada pensamento específico, cumpria, à luz do sistema todo, tentar ver tal pensamento em sua forma definitiva, isentado das variações, das flutuações inerentes à lição falada, depois encaixá-lo em seu meio natural, apresentando-lhes todas as partes numa ordem conforme a intenção do autor, mesmo quando semelhante intenção fosse mais adivinhada que manifestada. (BALLY, SECHEHAYE, 1916 [2006], p. 3) 
Bally e Sechehaye, no processo de elaboração do CLG, procuraram recriar o pensamento de Saussure a partir das fontes que lhes foram disponibilizadas, sabendo, contudo, que tal reconstrução jamais poderia ser de fato alcançada, visto que o que foi proferido por Saussure em suas aulas nunca pode ser recuperado em sua plenitude. Dessa forma, durante a edição, os editores procuraram seguir as pistas deixadas nos documentos fontes, tais como datas, ordem de apresentação dos conteúdos e reformulações, a fim de que pudessem chegar o mais próximo possível do que foi pensado e exposto por Saussure, em seus cursos acerca da Linguística Geral.

Entretanto, mesmo com o cuidado tomado pelos editores, o CLG, que já teria o estatuto de uma obra póstuma, organizada após a morte do autor ao qual as ideias são atribuídas, poderia, também, passar a ser contestada por não ser pautada em documentos que foram escritos pelo punho do próprio Saussure. No "Prefácio à Primeira Edição" do CLG, Bally e Sechehaye mostram-se cientes de que poderiam receber críticas tanto pela incompletude da edição, como por exporem, nela, pontos já tratados antes de Saussure. Mesmo assim, buscaram não negligenciar "nada que pudesse contribuir para a impressão do conjunto" (BALLY; SECHEHAYE, 1916 [2006], p. 3),

Devido a isso, os editores afirmam assumir toda a responsabilidade pela obra "perante a crítica, perante o próprio autor", isto é, Ferdinand de Saussure, e questionam se ele teria, com efeito, autorizado a publicação da edição (BALLY; SECHEHAYE, 1916 [2006], p. 4). Nota-se que, ao se referirem a Saussure como o autor do CLG, os editores reconhecem, desde já, que a edição é fruto de uma teorização pertencente ao linguista, mesmo que, para que se constituísse como livro, tivesse que passar por suas mãos. Além disso, eles se abstêm de qualquer mérito que possa sobressair da publicação do livro e, ao fazerem isso, atribuem a Saussure não só o sucesso da edição, mas, consequentemente, também o título, que veio mais tarde, de fundador da Linguística Moderna.

Por outro lado, Bally e Sechehaye se responsabilizam ainda pelas críticas de cunho negativo que pudessem surgir, com a publicação do CLG:

\begin{abstract}
Aceitamos integralmente semelhante responsabilidade e queremos ser os únicos a carregá-la. Saberá a crítica distinguir entre o mestre e seus intérpretes? Ficar-lhe-íamos gratos se dirigisse contra nós os golpes com que seria injusto oprimir uma memória que nos é querida. (BALLY; SECHEHAYE, 1916 [2006], p. 4)
\end{abstract}

Nota-se que os editores tomam para si todo o encargo pelos defeitos que possivelmente acometeriam a edição do CLG, e deixam para Saussure o mérito pelas reflexões e pela teorização nela apresentada. Assim, é perceptível que, desde já, uma posição acerca da autoria do CLG é tomada pelos editores e, devido à relevância do posicionamento dos dois no prefácio do livro, tal posição, a princípio, não é questionada pela comunidade que se dedicava aos estudos linguísticos.

Entretanto, com a recepção do CLG em diversas partes do mundo, e com o surgimento de mais de 30 mil folhas manuscritas de Saussure, vieram à tona posicionamentos distintos acerca da autoria do CLG. Muitos autores se mantiveram alinhados aos editores, atribuindo a autoria do livro ao linguista genebrino, ou, ao menos, não a questionando. Dentre esses autores destacamos Normand (2009), que propõe uma discussão consistente sobre o assunto. No entanto, há aqueles que se opõem ao posicionamento dos editores e colocam em xeque a autoria do curso, questionando se as intervenções feitas pelos editores não alterariam o "real" pensamento de Saussure. Destacamos Bouquet $(1997 ; 2002)$ como o principal autor que se alinha a esse pensamento.

Nesse sentido, no tópico a seguir apresentaremos o posicionamento de Normand (2009) e Bouquet (1997; 2002), de forma a contrapô-los, para que, em seguida, embasados por Foucault (1969), possamos compreender se, a partir da perspectiva desse autor, é possível de fato sustentar a autoria das reflexões que são atribuídas a Saussure. 


\section{A autoria do CLG: consensos e divergências}

O CLG, com o passar dos anos, adquiriu o estatuto de livro fundador da Linguística Moderna. Com isso, passou a ser leitura obrigatória nos cursos de Letras da Europa, primeiramente, e, depois, foi aos poucos alcançando seu lugar nas faculdades de diversas partes do mundo. Segundo Normand (2009),

O Curso de Linguística Geral, tal como, após sua morte [de Saussure], seus editores o haviam reconstruído a partir dos cadernos de notas dos estudantes, suscitou interesse e críticas sem que ninguém visse nele um barril de pólvora suscetível de ser ameaça à tradição universitária. Eis que, com a explosão dos anos de 1960, ele se encontrava sob a mesma bandeira de Marx e Freud, frequentemente acompanhados de Nietzsche, Lautréamont e Mallarmé, contra o velho mundo e seus valores rançosos. (NORMAND, 2009, p. 16)

À medida que isso ocorria, e com o crescimento das dimensões de alcance e de relevância do CLG e de seu conteúdo, discussões sobre as circunstâncias de sua elaboração começaram a ganhar lugar no universo de pesquisadores, em especial daqueles do âmbito da filosofia e da filologia. A descoberta de novos manuscritos saussurianos, nos anos de 1955 e 1968, também foi um aspecto notável, que motivou as investigações concernentes ao contexto da edição do livro. De acordo com Silveira (2016),

Parece-nos que os manuscritos recebidos por Bally, após a morte de Saussure em 1913, o grande volume de manuscritos disponibilizados em 1955 e 1968 e a descoberta de novos manuscritos em 1996 constituem três marcos importantes do trajeto desses manuscritos e impulsionaram o trabalho com eles, especialmente na França, na própria Suíça e na Itália. (SILVEIRA, 2016, p. 20).

Com a disponibilização desses manuscritos, principalmente das duas primeiras levas, alguns pesquisadores se dispuseram à tarefa de comparar o conteúdo do CLG com o conteúdo apresentado nos conjuntos de manuscritos, com a finalidade de contestar a autenticidade da edição. Bouquet $(1997 ; 2002)$ é um dos autores que se prestam a essa comparação e se posiciona de modo a afirmar que os editores do CLG falsearam o pensamento de Saussure. Segundo ele:

[...] essa obra oferece, por outro lado, um reflexo deformado do pensamento que pretende divulgar, falseando, sob dois importantes aspectos, as notas do curso e os manuscritos de Saussure em que se apoia. (BOUQUET, 1997, p. 13).

Os dois "aspectos importantes" aos quais Bouquet (1997) se refere consistem, em primeiro lugar, no fato de que o CLG é "organizado sob a lógica de um sistema acabado", a qual foi imposta, pelos editores, aos manuscritos de Saussure e às anotações dos participantes de seus cursos - documentos chamados pelo autor de "textos originais". O outro aspecto ressaltado por Bouquet (1997) trata-se do "discurso homogêneo" que supostamente circunda toda a redação do CLG. Para o autor, é essa homogeneidade do discurso que faz com que a "falsificação realizada pelos redatores" seja "mais profunda e insidiosa", uma vez que a coerência dos documentos saussurianos é significativamente diferente daquela apresentada no livro (BOUQUET, 1997, p. 14).

Esses dois aspectos em conjunto, na lógica de Bouquet (1997), fazem com que o CLG apresente um caráter muito mais positivista do que os manuscritos de Saussure, forçando à Linguística o estatuto de ciência dentre as áreas do conhecimento. Em contrapartida,

os enunciados originais de Saussure desenvolvem um pensamento infinitamente mais sutil e mais original: eles elaboram, ao mesmo tempo, o projeto de uma positividade (projeto mais radical que o do Cours, porque procura satisfazer uma epistemologia geral 
e não uma epistemologia ad hoc aplicável às ciências humanas) e uma especulação, que se apresenta, por contraste, como "filosófica", censurada enquanto tal por Bally e Sechehaye [...]. (BOUQUET, 1997, P. 16, grifos nossos).

Ao se posicionar de forma a rotular os manuscritos saussurianos como "textos originais" ou "enunciados originais de Saussure", em contraposição ao CLG - que seria, segundo ele, falseado -, Bouquet (1997) se inscreve num posicionamento discursivo que nega a Saussure a autoria do livro. Além disso, a questão da originalidade retorna, quando o autor trata não apenas dos documentos em si, mas também das ideias neles apresentadas - segundo ele, nos manuscritos, o pensamento de Saussure é apresentado de forma infinitamente mais original e mais sutil.

Ademais, o autor afirma existir uma censura de Bally e Sechehaye, no que concerne à especulação filosófica que caracteriza o pensamento de Saussure entendido, por Bouquet (1997), como original. Ora, afirmar a existência de censuras na edição do CLG significa acusar os editores de realizar interferências no texto de Saussure e nas anotações daqueles que estavam nos cursos, interferências estas que vão além da simples edição. Tomar tal posicionamento consiste em negar que as ideias apresentadas no CLG não são, de fato, de autoria de Saussure; são, na verdade; ideias distorcidas.

No prefácio do livro "Escritos de Linguística Geral”, que busca dar, ao público, acesso a uma transcrição de alguns manuscritos saussurianos, Bouquet (2002) se posiciona de forma semelhante:

[...] cabe hoje, ao comparar os manuscritos e as anotações dos alunos com a vulgata consagrada do Cours, apontar o maior alcance das meditações do genebrino - e de observar, também, que seu programa científico é, ao mesmo tempo, menos categórico que a sua tradução de 1916 e estabelecido sobre fundamentos mais minuciosamente explicitados. (BOUQUET, 2002, p. 12, grifo nosso).

Novamente, Bouquet (2002) nega que o CLG apresente o real pensamento de Saussure, afirmando que tal pensamento é, com efeito, menos categórico e mais bem fundamentado características que, para ele, são reveladas pelos manuscritos e pelos cadernos dos participantes dos cursos do linguista. Dessa forma, parece clara a posição de Bouquet quanto à autoria do CLG: ele não considera que as ideias apresentadas no livro sejam, tais como são expostas, frutos das reflexões do linguista genebrino. Para ele, o "verdadeiro" Saussure só pode ser encontrado em seus manuscritos autógrafos e nos cadernos dos participantes de seus cursos. Nesse sentido, vemos que, para o autor, as peculiaridades de elaboração e a edição de Bally e Sechehaye consistem em fatores que retiram a possibilidade de atribuir a Saussure a autoria do CLG.

O posicionamento de Bouquet é amplamente contestado entre os pesquisadores que se dedicam às questões Saussurianas. Sobretudo após o surgimento da última leva de manuscritos, em 1996, questionar a legitimidade de uma obra que é, hoje, considerada responsável pela fundação da Linguística Moderna consiste em nada menos que questionar a própria fundação dessa área do conhecimento. De acordo com Silveira (2016),

[...] com a chegada dos novos manuscritos em 1996 e a crítica generalizada que Bouquet fez aos editores dos primeiros manuscritos, o mal-estar se generalizou e os trabalhos se encaminharam para outra direção, já que a questão da "fidelidade" entre os manuscritos e o CLG estava colocada e não foi bem aceita por grande parte dos pesquisadores da fortuna saussuriana. (SILVEIRA, 2016, p. 20).

Normand (2009), como já afirmamos, situa-se entre os autores que se posicionam de forma antagônica a Bouquet. Para a autora, mesmo que o CLG não tenha sido efetivamente escrito por Saussure, mesmo que seja uma obra póstuma, editada por dois discípulos do linguista 
genebrino, ainda assim trata-se de um livro que carrega as reflexões feitas por Saussure durante todo o percurso de seus estudos da linguagem, desde o período que atuou como comparatista até o momento em que assumiu a cadeira de Linguística Geral, na Universidade de Genebra.

O posicionamento da autora é bastante claro em seu livro intitulado "Saussure", no qual afirma que:

[...] esse texto [o CLG], muitas vezes reeditado e traduzido, continuarei, segundo a tradição, a chamá-lo de Saussure. Não se trata, evidentemente, de ignorar os trabalhos filológicos, mas de resguardar-lhes seu papel de complemento e de correção eventual, recusando que eles sejam obstáculos a uma primeira reflexão sobre o Curso como texto, único texto facilmente legível de modo corrente, um texto para ser lido como tantos outros o fizeram com grande proveito. (NORMAND, 2009, p. 18, grifo da autora).

Normand (2009) considera que os trabalhos filológicos - de catalogação, de agrupamento e de análise das formas dos manuscritos - consistem em complementos para as reflexões acerca da teorização de Saussure e ressalta que apenas o CLG pode oferecer uma leitura desprovida de impasses provocados pelos aspectos formais dos manuscritos. Tal fato favorece a compreensão e as discussões que envolvem o aparato teórico saussuriano, possibilitando que as pesquisas sobre o tema tenham um material consistente, no qual possam se ancorar.

Dessa forma, para a autora, o CLG ainda hoje é uma obra de leitura obrigatória para aqueles que se dedicam aos estudos linguísticos. Ao opor o CLG a um suposto pensamento autêntico de Saussure, questiona-se todo o conteúdo que permitiu que fosse instaurada a Linguística enquanto ciência. Ora, se a teorização que compõe a edição é sólida o bastante para dar as bases de fundação de uma ciência, podemos supor que a organização do livro, de forma geral, foi, de fato, bem-sucedida. Ademais, tendo em vista semelhante solidez, opor o conteúdo da edição ao conteúdo dos manuscritos significaria, então, contestar a genialidade das reflexões de Saussure?

Normand (2009) também considera o CLG como uma referência para o pensamento moderno, sobretudo no que se refere ao período em que se estabeleceu o estruturalismo. A esse respeito, a autora afirma que:

Esse texto que o "mestre" não escreveu, não achou por bem escrever, a história da linguística e, mais amplamente, do pensamento moderno (aquele das ciências sociais), dele se apropriou, tornando-o, durante todo o período dito "estruturalista", um emblema e uma referência. (NORMAND, 2009, p. 20).

Há, nos parece, um quê de ironia no início do trecho acima. Ao se referir ao CLG como "o texto que o 'mestre' não escreveu", mas que mesmo assim se consagrou no âmbito das ciências sociais, Normand se inscreve numa posição contrária à de Bouquet, a qual expusemos anteriormente. Nessa perspectiva, é notável que a autora se afasta de questionamentos acerca da autenticidade do CLG e da fidelidade dos editores para com o pensamento de Saussure. Dessa forma, ela relativiza a afirmação de que o linguista não seja de fato autor do livro e rememora, também, que, independentemente disso, o CLG foi o precursor da Linguística estrutural e um divisor de águas nesse terreno.

As posições tomadas por Bouquet (1997; 2002) e Normand (2009) acerca da autoria do CLG são, claramente, antagônicas. Embora o posicionamento do primeiro autor seja bastante criticado por pesquisadores tradicionais das reflexões saussurianas, consideramos importante abordá-la em nosso trabalho, em contraste com o posicionamento de Normand (2009), para que possamos refletir, a partir do conceito foucaultiano de autor, sobre a atribuição da autoria do CLG a Saussure. Por isso, no tópico a seguir apresentaremos alguns elementos que embasam a 
discussão proposta por Foucault acerca da autoria, a fim de que, posteriormente, coloquemos em pauta a questão do CLG, a partir da ótica do filósofo.

\section{A função autor em Foucault}

No decorrer de suas elaborações, Foucault trata, algumas vezes, do conceito de função autor, de forma a relacioná-lo ao discurso e, consequentemente, ao sujeito. Em "A ordem do discurso", Foucault (1970) concebe o conceito de função autor como um princípio de rarefação do discurso. Nesse sentido, não é entendido como o indivíduo que pronuncia ou escreve um texto, mas como aquilo que dá unidade a um discurso específico.

O autor, não entendido, é claro, como o indivíduo falante que pronunciou ou escreveu um texto, mas o autor como princípio de agrupamento do discurso, como unidade e origem das suas significações, como foco da sua coerência. (FOUCAULT, 1996 [1970], p. 25).

A ideia de indivíduo, no conceito de função autor, é colocada como secundária para Foucault, uma vez que a autoria não depende exclusivamente da existência de alguém que seja responsável pela produção de textos e falas. Mais do que isso, o autor é um princípio que reúne discursos determinados a partir de posicionamentos sociais, políticos e disciplinares, e que surge quase que somente "nos domínios onde a atribuição de um autor é de regra - literatura, filosofia, ciência [...]” (FOUCAULT, 1996 [1970], p. 25).

Apesar de secundária, a existência de um indivíduo relacionada ao conceito de função autor não é negada por Foucault. Para ele, é "absurdo negar, é claro, a existência do indivíduo que escreve e inventa" (FOUCAULT, 1996 [1970], p. 27). Entretanto, o fato de o autor ser um princípio - ou uma função - e não apenas um indivíduo, acarreta a existência de um funcionamento que exige a institucionalização do discurso para que ele seja vinculado a uma autoria, distanciando-o das conversas cotidianas e dos outros tipos de discursos que não exigem esse tipo de atribuição. O que distingue esses dois tipos de discurso são aspectos como i) sobre o que se diz; ii) quem diz sobre o que se diz; iii) que instituições validam o que se diz sobre o que alguém disse Esse funcionamento incide desde a criação - ou concessão - de um nome de autor a um agrupamento específico de práticas discursivas que têm significações específicas.

Em seu trabalho intitulado "O que é um autor", de 1969, Foucault apresenta dois questionamentos principais, relacionados ao uso do nome do autor. São eles: "O que é o nome do autor?" e "Como ele funciona?" (FOUCAULT, 2001 [1969], p. 272). Contudo, em vez de apresentar soluções diretas para essas questões, Foucault as problematiza, indicando algumas dificuldades que o nome de autor apresenta. A primeira delas consiste no fato de que um nome de autor é, antes de tudo, um nome próprio, o que faz com que sua forma de referenciação não seja pautada simplesmente em uma indicação de significação, em uma designação; para além disso, o nome de autor tem como referente uma série de descrições que o vinculam diretamente a um tema ou a uma área do conhecimento à qual seu(s) texto(s) corresponde(m).

Por exemplo, o nome "Ferdinand de Saussure" é equivalente a uma série de descrições que o aproximam - e, consequentemente, podem distanciá-lo - do título de "fundador da Linguística Moderna" ou de "autor do Curso de Linguística Geral". Entretanto, não é apenas a característica descritiva que define o nome de autor. Se se coloca em pauta o fato de que o Curso é uma obra póstuma e não foi, literalmente, escrito por Saussure, mesmo assim a relação do nome do linguista aos acontecimentos a ele vinculados (como a publicação do CLG, o estabelecimento d conceito de língua etc., a escrita do Mémoire) não é alterada. Desse modo, notase que o nome de autor se situa entre a designação e a descrição, uma vez que há certa ligação 
com o que ele nomeia, embora tal ligação não seja categórica, de forma a estabelecer uma designação, um sentido.

Ademais, essas duas características do nome do autor - de se relacionar com o indivíduo nomeado e com o que ele nomeia - não se dão na mesma medida, isto é, não são isomorfas. É por esse motivo que o nome de autor não é um nome próprio como todos os outros. Ele não é apenas um elemento componente de um discurso, que pode ser substituído por outras formas coesivas ou que é usado unicamente como elemento sintático. Considerado em relação ao discurso, o nome de autor exerce um papel determinado, e possui a função classificatória de delimitar os textos e reagrupá-los, vinculando-os a determinado nome e, por conseguinte, separando-os e opondo-os a outros textos (FOUCAULT, 2001 [1969], p. 274).

Dito de outro modo, o nome de autor tem como função diferenciar a palavra cotidiana, que é instantaneamente consumivel e passageira, de um discurso especifico, que deve ser recebido de uma maneira especifica e ao qual deve ser atribuido certo status (FOUCAULT, 2001 [1969]). O nome de autor é um dos principais elementos que estabelecem a ruptura que certo grupo de discursos exige e que evidencia suas características particulares. Ademais, segundo Foucault (2001 [1996]), é importante ressaltar que há, na sociedade, discursos que apresentam a função autor e outros que não apresentam; por exemplo, uma carta pode ser assinada por alguém, mas não possuir um autor, pois seu discurso não necessita de um funcionamento específico e nem tem necessidades criteriosas de circulação e de funcionamento no interior da sociedade.

É por esse motivo que Foucault (2001 [1996], p. 273) afirma que o nome de autor tem como função caracterizar um modo de ser do discurso. Ou seja, para ele, a autoria funciona como um elemento diferenciador entre as falas cotidianas e um discurso de caráter relevante para determinada sociedade ou para grupos que compartilham crenças e/ou princípios. A atribuição de um autor a algo que foi dito ou escrito é uma necessidade que se impõe quando se torna necessário dar relevo a determinado discurso, quando algo que foi dito precisa ser recebido e analisado diferentemente daquilo que é dito cotidianamente, a fim de que receba um status específico.

Nesse sentido, consideramos relevante destacar as quatro características da função autor, delimitadas por Foucault (2001 [1969]). A primeira delas consiste no fato de que os discursos portadores dessa função são objetos de apropriação. Isso significa dizer que a delimitação da autoria dos discursos, bem como das regras, dos direitos e dos deveres de autores e editoras, faz com que eles sejam colocados no sistema de propriedades típico da sociedade atual. Essa necessidade de delimitação de um "regime de propriedade para textos" nasceu da possibilidade de punição destinada àqueles que, em seus discursos, transgrediam, iam além do que era socialmente permitido.

Como segunda característica, Foucault (2001 [1969]) ressalta que a função autor "não é exercida de maneira universal e constante em todos os discursos". Ou seja, ao longo dos anos e em diferentes civilizações, os tipos de textos para os quais é exigida a autoria podem se modificar. $\mathrm{Na}$ Idade Média, por exemplo, a circulação de textos literários não dependia de sua relação com um autor; hoje em dia, Foucault afirma que o "anonimato literário não é suportável", não podendo um texto de ficção com autor indefinido circular na sociedade sem que cause inquietações (FOUCAULT, 2001 [1969], p. 276).

A terceira característica desfaz o conceito que, muitas vezes, se tem do autor, no sensocomum: a função autor não se dá de forma espontânea, por meio da atribuição de um discurso a um autor. Como já foi destacado anteriormente, o autor não é apenas um indivíduo, mas um ser de razão; do indivíduo, designa-se como autor aquilo que constitui o modo como se constrói o discurso: o tratamento que se dispensa aos textos, as aproximações, as exclusões e mesmo as continuidades.

A quarta e última característica de todos os discursos que possuem a função autor é a ocorrência de uma pluralidade de ego. É possivel, por exemplo, em uma mesma obra, encontrar 
simultaneamente três egos que se dispersam, cada qual com um propósito, mas que, em conjunto, constituem um discurso autoral (FOUCAULT, 2001 [1969]). Lembramos que a função autor não remete puramente a um indivíduo real, mas daquilo, no indivíduo, que permite a concomitância dessas diferentes faces.

Para finalizar a exposição do conceito de função autor em Foucault, mostra-se relevante que abordemos, também, o que o autor considera como obra. A esse respeito, ele coloca algumas questões, dentre as quais salientamos, sobretudo, as seguintes:

“[...] Uma obra não é aquilo que é escrito por um autor?" Veremos as dificuldades
surgirem. Se um indivíduo não fosse um autor, será que se poderia dizer que o que ele
escreveu, ou disse, o que ele deixou em seus papeis, o que se pode relatar de suas
exposições, poderia ser chamado de "obra"? Enquanto Sade não era um autor, o que
eram então esses papéis? Esses rolos de papel sobre os quais, sem parar, durante seus
dias de prisão, ele desencadeava seus fantasmas.
Mas suponhamos que se trate de um autor: será que tudo o que ele escreveu ou disse,
tudo o que ele deixou pra trás de si faz parte de sua obra? (FOUCAULT, 2001 [1996],
p. 269).

Nota-se, com base no trecho acima, que o conceito de obra não pode ser discutido separadamente do conceito de função autor. O que compreende a obra de determinado autor só pode ser delimitado a partir do momento em que compreendermos que esse autor, como já ressaltamos, não se trata do indivíduo em si, mas de uma função que permite o agrupamento de discursos, de forma a reuni-los a partir das significações que os perpassam. Isso porque, segundo Foucault (2001 [1969], p. 270), “a palavra 'obra' e a unidade que ela designa são provavelmente tão problemáticas quanto à individualidade do autor".

A partir do exposto, consideramos produtivo tecer algumas considerações, relacionando as reflexões de Foucault acerca das que envolvem autor e obra com a problemática em torno da autoria do CLG.

\section{$4 \mathrm{O}$ autor "Saussure"}

Tendo em mente as questões acerca da autoria do CLG abordadas no primeiro tópico deste trabalho, bem como a delimitação do conceito de função autor para Foucault exposta no tópico anterior, procuraremos apontar alguns elementos que permitam refletir se é possível, a partir da perspectiva de Foucault, sustentar a concessão da autoria do CLG a Saussure, tal como foi feito desde sua primeira publicação, em 1916, com base no pronunciamento feito pelos editores no prefácio do livro.

A primeira questão a ser considerada consiste no fato de que o conceito foucaultiano de autor se relaciona apenas de forma secundária ao indivíduo que escreve ou que fala. A função autor se relaciona mais intimamente com o agrupamento de discursos, que originam determinadas significações. Desse modo, alegar que a autoria do CLG não deva ser concedia a Saussure pelo fato de o livro não ter sido efetivamente escrito por ele - tal como faz Bouquet não é um argumento válido, na perspectiva foucaultiana. Uma vez que as ideias apresentadas na edição correspondem às reflexões expostas por Saussure em seus cursos, estabelece-se uma relação de agrupamento discursivo, que tem como foco a coerência dos enunciados do linguista, e que permitem restabelecer e compreender o funcionamento das regras que tornam Saussure um nome de autor, num certo contexto e numa determinada época.

Por outro viés, podemos analisar a contraposição, defendida por Bouquet, entre os "textos originais de Saussure", isto é, seus manuscritos e os cadernos dos participantes de seus cursos, e a edição do CLG. Se considerarmos o posicionamento de Foucault acerca da delimitação de obra, de forma correlacionada à função autor, veremos que, mais do que separar 
ou dividir os escritos e falas de um autor, a fim de delimitar um único corpus que possa ser atribuído a ele, devemos somá-los e considerar todos os suportes que carregam suas reflexões como elementos de sua obra. Segundo Foucault:

\footnotetext{
Quando se pretende publicar, por exemplo, as obras de Nietzsche, onde é preciso parar? É preciso publicar tudo, certamente, mas o que quer dizer esse "tudo"? Tudo o que o próprio Nietzsche publicou, certamente. Os rascunhos de suas obras? Evidentemente. Os projetos dos aforismos? Sim. Da mesma forma as rasuras, as notas nas cadernetas? Sim. (FOUCAULT, 2001 [1969], p. 210).
}

Dessa forma, considerar Saussure como autor do CLG não impede que também o consideremos como autor dos manuscritos ou das ideias anotadas nos cadernos dos participantes dos cursos. Trata-se de materiais de cunhos diferentes e, portanto, devemos considerar suas peculiaridades. Além disso, a teorização de Saussure não se mostra linear e nem teleológica, em nenhum dos documentos que se tome como base. Mesmo no CLG, que é considerado por muitos como uma obra que busca introduzir uma teorização acabada, há indícios de um movimento de uma teorização em processo.

É possível também observar a questão da autoria do CLG a partir da ótica de algumas das características atribuídas, por Foucault, à função autor. Ressaltemos, de início, a terceira característica: "a função autor não se dá de forma espontânea, por meio da atribuição de um discurso a um autor". A autoria não consiste em algo que possa ser atribuído ou não a alguém pela simples vontade de um indivíduo ou de um grupo de pessoas. O CLG foi publicado em 1916 sob autoria de Ferdinand de Saussure, e foi aceito pelo público dessa forma.

As questões acerca de sua legitimidade e da fidelidade dos editores foram trazidas à tona e culminadas por Bouquet em um momento em que a relação de autoria e obra entre Saussure e o Curso já havia sido instaurada e, mais do que isso, já havia concedido ao linguista o estatuto de fundador da Linguística Moderna. Colocar em xeque uma autoria já estabelecida e bem fundada, por meio de um movimento retrógado, a nosso ver, deve ser um trabalho que apresente como fundamentos mais do que questões que incidem no estilo da redação e na efetividade da escrita que originou a edição.

A quarta característica da função autor - isto é, a pluralidade de ego - justifica de forma satisfatória a tomada de posição de Normand, que considera Saussure autor tanto do CLG, como dos seus manuscritos autógrafos e mesmo das ideias apresentadas nos cadernos dos participantes de seus cursos. Segundo Foucault, é possível encontrar, ao mesmo tempo, em trabalhos do mesmo autor, egos distintos que se espalham, cada um com uma finalidade, mas que, em conjunto, constituem um discurso autoral. Assim, não é necessário que o Saussure que se apresenta no CLG seja o mesmo que se apresenta nos outros documentos, para que ele se constitua como autor. Pode haver diferenças na forma como se dão as práticas discursivas, desde que os discursos tenham pontos em comum suficientes para permitirem um agrupamento.

Por fim, destacamos a afirmação de Foucault de que uma das funções do nome do autor é separar a palavra cotidiana dos discursos que merecem uma recepção específica e aos quais deve ser atribuído determinado status. Ora, é inegável que a teorização apresentada no CLG tenha estatuto de um discurso fundador - tanto que, após sua publicação, foi atribuída a ele, como já afirmamos, o estatuto de livro fundador da Linguística Moderna. Além disso, mesmo que haja características estruturais ou de estilo de redação, o conteúdo do CLG vai na mesma direção do conteúdo que compõe grande parte dos manuscritos de Saussure em que são abordadas questões de Linguística Geral.

Nessa perspectiva, parece claro que não faz sentido contestar, tal como faz Bouquet, que Saussure seja autor do CLG, alegando que haja interferência significativa dos editores. Ademais, atribuindo ao linguista a autoria do CLG, as reflexões apresentadas no livro são recebidas não 
como um discurso cotidiano, mas com um status específico, dispensado nomeadamente pela comunidade linguística e pelos âmbitos do conhecimento que estão a ela relacionados.

\section{CONSIDERAÇÕES FINAIS}

Neste trabalho, nos propusemos a analisar a concessão da autoria do CLG a Saussure, a partir da perspectiva do conceito foucaultiano de função autor. Para isso, apresentamos primeiramente o contexto de elaboração do CLG e, em seguida, expusemos os posicionamentos de Bouquet (1997; 2002) e Normand (2009), acerca da legitimidade da edição e de sua fidelidade ao pensamento saussuriano. Trata-se de posicionamentos antagônicos, uma vez que o primeiro contesta que Saussure seja autor do CLG, e a segunda, por sua vez, se posiciona a favor da concessão da autoria do livro ao linguista genebrino.

Em seguida, mostramos como o conceito de função autor se estabelece em Foucault (1969; 1970), de forma a considerar o indivíduo apenas como elemento secundário. Isso significa dizer que, para que haja um autor de uma obra, mais do que um indivíduo, é preciso que haja um agrupamento de discursos, que tenha como foco a coerência. Além disso, segundo Foucault, pode haver pluralidade de egos em uma mesma obra de determinado autor, e os diferentes suportes materiais que carregam os discursos de cunho autoral devem ter sua autoria atribuída ao autor ao qual eles se relacionam.

Desse modo, considerando as exposições e as análises realizadas anteriormente, foi possível perceber que, pela ótica de Foucault, é possível sustentar, com efeito, a atribuição da autoria do CLG a Saussure.

\section{REFERÊNCIAS}

BALLY, C.; SECHEHAYE, A. Prefácio à primeira edição. In: SAUSSURE, F. Curso De Linguística Geral. Trad. de A. Chelini; J. P. Paes e I. Blikstein. 27ª Ed. São Paulo: Cultrix, 2006.

BOUQUET, S. Introdução à leitura de Saussure. Trad. De C. A. L. Salum; A. L. Franco. 9a Ed. São Paulo: Cultrix, 1997.

Prefácio dos editores. In: SAUSSURE, F. Escritos de Linguística Geral. Trad. De C. A. L. Salum; A. L. Franco. 12a Ed. São Paulo: Cultrix, 2002.

FOUCAULT, M. O que é um autor? [1969]. In: FOUCAULT, M.; MOTTA, M. B. (Org.). Michel Foucault - Estética: Literatura e Pintura, Música e Cinema. Trad. De I. A. D. Barbosa. Rio de Janeiro: Forense Universitária, 2001.

A ordem do discurso: aula inaugural no Collège de France, pronunciada em 2 de dezembro de 1970. Trad. De L. F. A. Sampaio. 24ª Ed. São Paulo: Edições Loyola, 1996.

NORMAND, C. Saussure. Trad. De A. Alencar; M. Diniz. São Paulo: Estação Liberdade, 2009.

SILVEIRA, E. M. As marcas do movimento se Saussure na fundação da Linguística. Campinas, SP: Mercado de Letras, 2007. 
A difícil relação entre os manuscritos e o Curso de Linguística Geral. In: CRISTIANINI, A. C.; OTTONI, M. A. R. (Orgs.); Estudos Linguísticos: teoria, prática e ensino. Uberlândia, EDUFU, 2016.

Submetido em 13/11/2018

Aceito em 07/05/2019

Publicado em 04/06/2019 